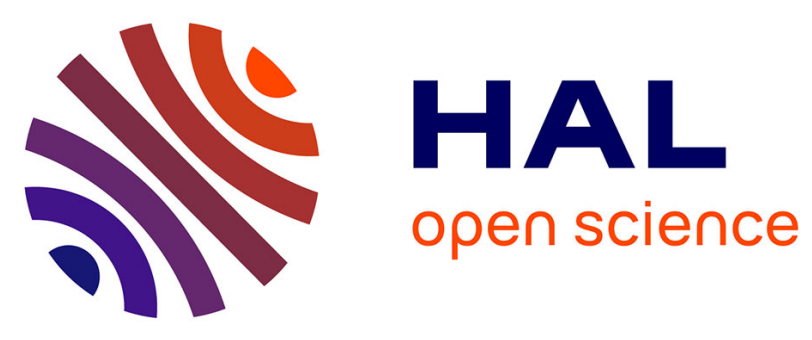

\title{
Electrical Energy Management for Advance Smart Home Systems: Introduction
}

M Nassereddine, J Rizk, A Hellany, M Nagrial, A Elrafhi, Z Obeid, Khaled Hajar

\section{- To cite this version:}

M Nassereddine, J Rizk, A Hellany, M Nagrial, A Elrafhi, et al.. Electrical Energy Management for Advance Smart Home Systems: Introduction. International Conference on Renewable Energies for Developing countries (REDEC 2016), Jul 2016, Zouk Mosbeh, Lebanon. hal-01334817

\section{HAL Id: hal-01334817 https://hal.science/hal-01334817}

Submitted on 21 Jun 2016

HAL is a multi-disciplinary open access archive for the deposit and dissemination of scientific research documents, whether they are published or not. The documents may come from teaching and research institutions in France or abroad, or from public or private research centers.
L'archive ouverte pluridisciplinaire HAL, est destinée au dépôt et à la diffusion de documents scientifiques de niveau recherche, publiés ou non, émanant des établissements d'enseignement et de recherche français ou étrangers, des laboratoires publics ou privés. 


\section{Electrical Energy Management for Advance Smart Home Systems: Introduction}

\author{
M. Nassereddine, J. Rizk, A. Hellany, M. Nagrial \\ School of Computing, Engineering \& Mathematics \\ Western Sydney University \\ Penrith, Australia \\ m.nassereddine@,westernsydney.edu.au
}

\begin{abstract}
Electrical power energy forms an indispensable part of human comfort. Numerous activities would have been impossible without the aid of electricity. The introduction of the PV solar system introduces additional challenges to engineers on how to increase the efficiency of the system. Micro grid PV generations spread world-wide by installing small size PV system on the roof top of residential properties. The maximum output of the PV system is at midday where working families are away from homes. Without the storage system, this energy can only be injected into the electrical grid. This paper introduces the concept of electrical management system for smart home. The proposed smart system allows percentage of the $P V$ generated energy to be used during working hours. Also, the proposed system gives the individual a total control to maximize the use of generated energies, reduce the electricity bills and the impact on the environment. Case study is included
\end{abstract}

Index Terms-Electrical Power, House Consumption, Smart Technology.

\section{INTRODUCTION}

Electrical energy forms an indispensable element when it comes to human comfort. Numerous activities wouldn't be possible without the aid of the electrical energy. The production and consumption of the electrical power impact on the human budget as well as the environment. To reduce the cost of the fossil fuel power, and to reduce the impact on the environment, the installation of renewable energy sources increased dramatically in the past two decades [1]. Individuals are investing in micro-generation system that can be installed at their premises. For example, in Sydney, large number of houses installed small size PV solar panels on their roof to reduce the impact on climate change and reduce the electricity bill. According to the Australian Energy Council [2], 1.42 million small-scale solar power systems were installed across Australia by the end of 2014. The high percentages of these installed systems are grid connected without energy storage banks.

This large number of small PV solar generation reduces the energy consumption that is generated by the fossil fuel. However, the PV solar installation didn't reduce the maximum demands required from the power stations during the peak hours (morning and night). The morning peak hours are usually between 06:00 and 08:00am; the sun energy at this time will be at its minimum and won't assist with the electrical power

\author{
A. Elrafhi, Z. Obeid, K. Hajar \\ School of Engineering \\ University of Technology and applied Science \\ Tripoli, Lebanon \\ Ahmad.rafhi@ulf.edu.lb
}

demands. Based on this information, the electrical generation utilities cannot reduce its electrical infrastructure.

The works in this paper introduce the smart management system that enhance the efficiency of using the sun energy and allow for the reduction of the electrical generation infrastructure. The paper shows the innovative architect diagram between the smart grid and advance home technologies that lead to higher electrical power system efficiency. The case study validates the theoretical discussion within the paper.

\section{THEORETICAL STUDY}

The increase in electrical power demands forces engineers to focus on increasing the efficiency and the reliability of the entire power system. Researchers use smart grid technologies to enhance the performance of the power system. The smart grid collects information from distributions, generations and transmission using the latest information and communication technologies [3]. The optimizations in smart grid network enhance the overall network performance by increasing its reliability [4]-[6].

The installation of the solar PV panels on houses introduces the micro-generation source at the house. The output of the solar panels depends on the sun radiation energy. Figures 1 and 2 show the average hourly solar distribution and electrical loading for residential customers [7], [8]. The figures show that the generated power from the solar system without energy storage doesn't meet the electrical demands during peak hours for the residential house. The high cost of electrical storage prevent individual from investing into this technologies.

The paper idea is to enhance the electrical management system within residential houses. The system aims in maximizing the use of sun energy during the day and reducing the demands at evening and night. 


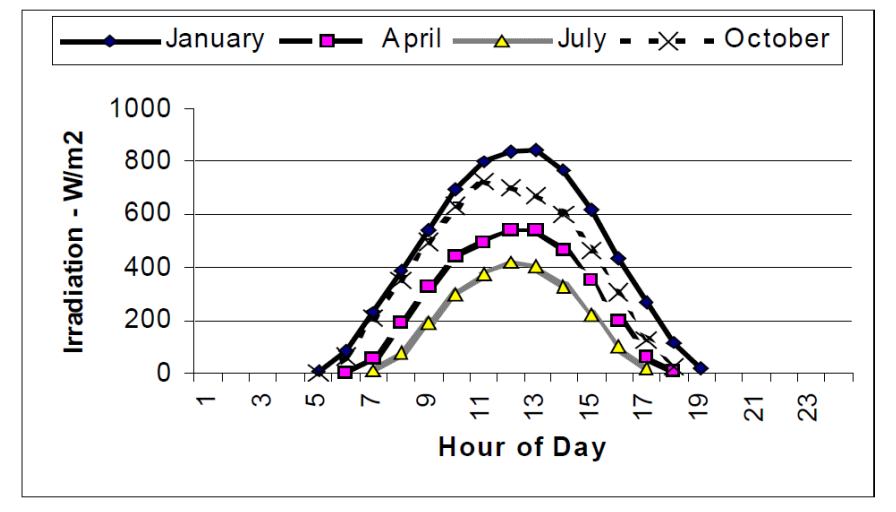

Figure 1. Solar hourly energy distribution [7]

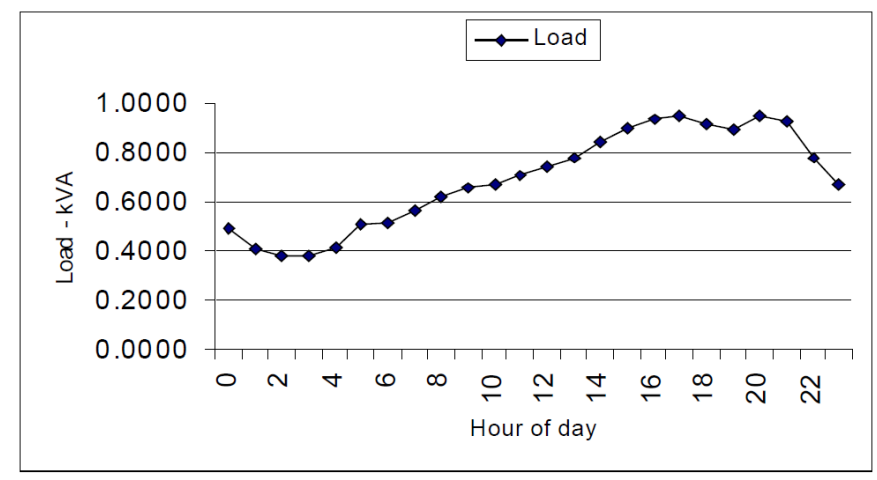

Figure 2. Electrical loading for residential property [7]

\section{A. House Hold Energy Consumption}

The average working hours in Sydney Australia are between 08:30 and 17:00 Monday to Friday. During this period, home energy consumption is at its minimum. Sydney school hours are 07:40 to 15:00. After these hours, the following activities are responsible for increase in energy usage:

- Air-conditioning

- Cooking

- Lighting

- Washing

- Drying

Performing any of the above activities between 11:00 and 15:00 on a sunny day, it reduces the evening energy consumption and the cost of energy bill for individual.

\section{B. $\quad$ Proposed Architect Diagram}

Figure 3 represents the proposed smart management architect diagram for individual houses. The system provides the individual with a predicted energy forecast from the solar system, based on hourly layout, and possible activities that can be performed to maximize the use of the solar energy.

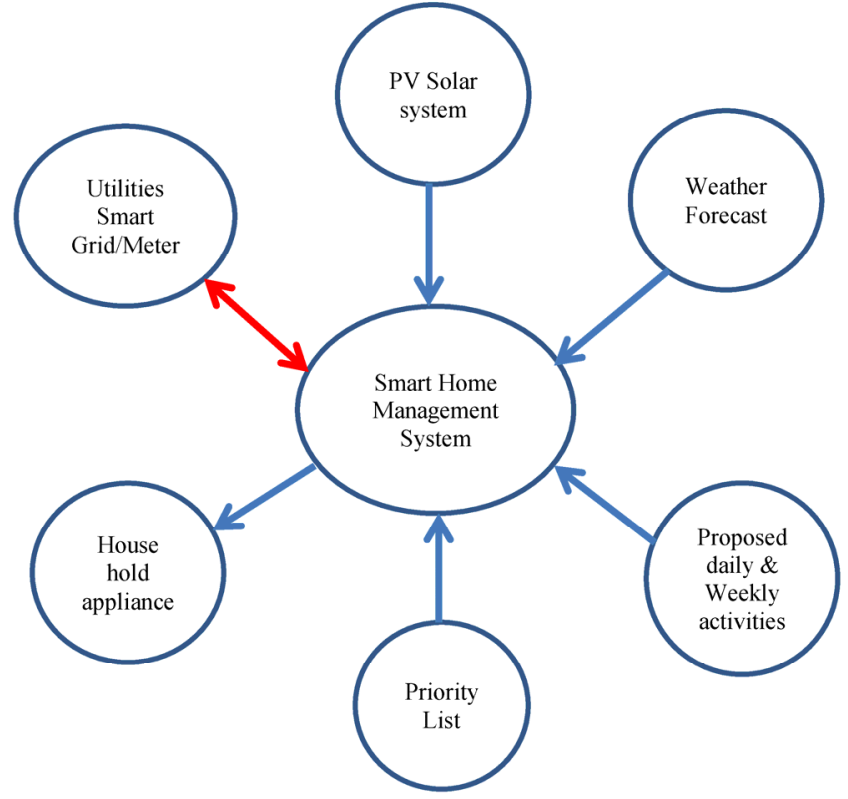

Figure 3. Proposed smart home management system

The proposed smart home management system has the following capabilities:

- Analyzes the weather forecast data (sunlight, humidity, heat, Etc...) for the area and determine its impacts on the output of the PV solar system.

- Provide the individual of the predicted electrical output from the installed PV system based on the weather forecast data. It allows the individual to plan certain activities based on the forecast data.

- Monitor the performance of the PV solar system. It logs all its operation and provides report to the individual when requested. The report can cover the used percentage of the generated power within the house.

- Assess the instantaneous electric power generated from the PV modules and advise on a possible use within the house

- Monitor the energy consumptions of the household electrical appliances (lights, oven, Aircondition, Etc...)

- Control the energy distribution between household appliances.

- Provides the individual with the opportunity to prioritize the use of generated power (create priority list).

- Manage the surplus generated power to reduce the peak demands in the afternoon. For example, the system can use the excessive energy to cool the house, complete the washing, drying, cooking, etc... 
- $\quad$ Log all the proposed weekly activities and provide an efficiency report based on the weather forecast.

- Two ways data between the house and the utility electrical smart grid. The utility can use this system to inform the individual of proposed outages or system malfunction updates. Also, it is possible to predict the area electrical forecast based on the proposed weekly activities.

- For a PV system with electrical storage device, the utility can utilities the storage energy if required and approved by the owners. This principle might be adopted by the electrical companies as it might reduce the investment within the electrical infrastructure.

- For standalone system, it can manage the system to protect the battery:

○ Setting the PV electrical energy priority to the load

- Maximize the use of the surplus electrical power during the daylight and reduce the energy consumption during the night

- Access throughout smart decides such as mobile phones. Individual can track and monitor the system while away.

- Provide an overall performance report. This provides individual with the opportunity to enhance the system efficiency.

\section{Calculations}

The electrical energy consumed by the house can be computed using equation 1 :

$$
P=K+O+L+G+M
$$

Where

$\mathrm{P}$ is the total daily power consumed by the house (Wh)

$\mathrm{K}$ is the air-condition power $(\mathrm{Wh})$

$\mathrm{O}$ is the cooking power (Wh)

$\mathrm{L}$ is the lighting power (Wh)

$\mathrm{M}$ is the washing and cleaning machines power $(\mathrm{Wh})$

$\mathrm{G}$ is the general power (Wh) (Fridge, hair dryer, mixer....)

For working family, K, O, M, and G are usually consumed when people arrived home after work or school. Therefore, it is main impacts will be after 15:00 hours. Figure 4 shows the energy consumption of a standard residential house of $20 \mathrm{kWh}$ daily energy usage. Figure 5 shows the electrical power outputs for a $5 \mathrm{~kW}$ PV solar system during summer and winter. The figure shows that major house electrical consumptions sit outside the PV generated power. This also confirms that PV outputs do not support the electrical peak maximum demands without the presence of the batteries storage.

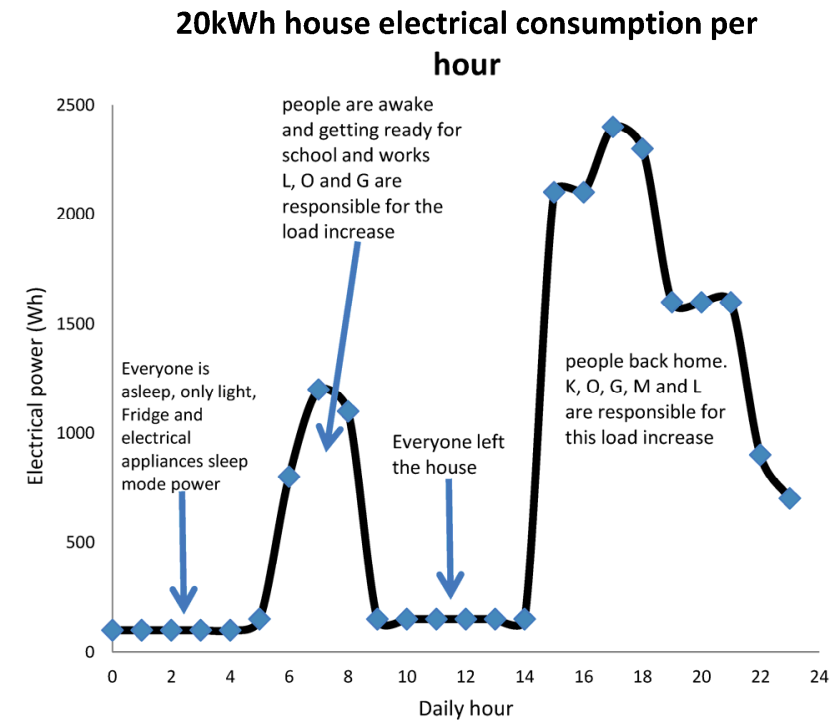

Figure 4. 20kWh house electrial hourly consumption

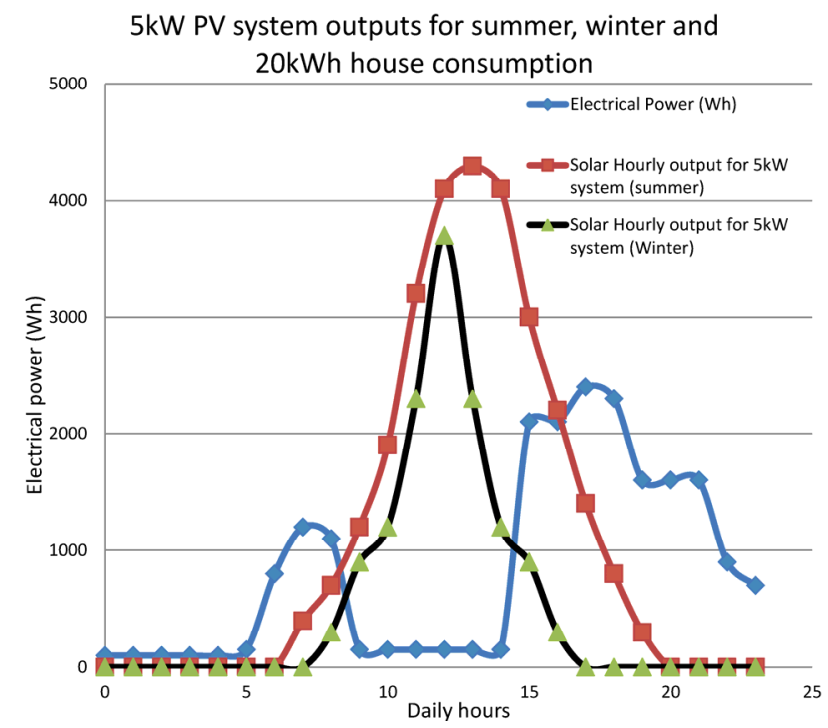

Figure 5. 5kW PV systen outputs for summer and winter

The following can be concluded from figure 5:

- $\quad$ Shifting the morning or afternoon loads to midday on a sunny day will reduce the maximum demands from the utility grids

- It also reduce the electrical energy bills for the properties

$\mathrm{G}$ and $\mathrm{L}$ form the main electrical power consumption for a working family between 09:00 and 15:00. Using the smart house management system to shift the following energy consumption to the midday activities:

- "M" run the washing machine, dryer and dishwasher between $11: 00$ and 14:00 on a sunny day 
- "K" run the air-condition between 13:00 and 15:00 on a sunny day. This will cool down the house and provide the individual with the opportunity to run the air-condition at lower power when they arrive home (save on electrical energy in the afternoon)

- "O" perform the cooking, especially the electrical oven, where possible between 11:00 and 14:00 on sunny day.

- The times and dates the machines should operate can be determined by the smart house management system and its ability to predict the PV electrical outputs.

Figure 6 shows the updated house hourly energy consumption against the PV solar outputs. It is clearly shown the reduction in energy consumption in the afternoon peak period.

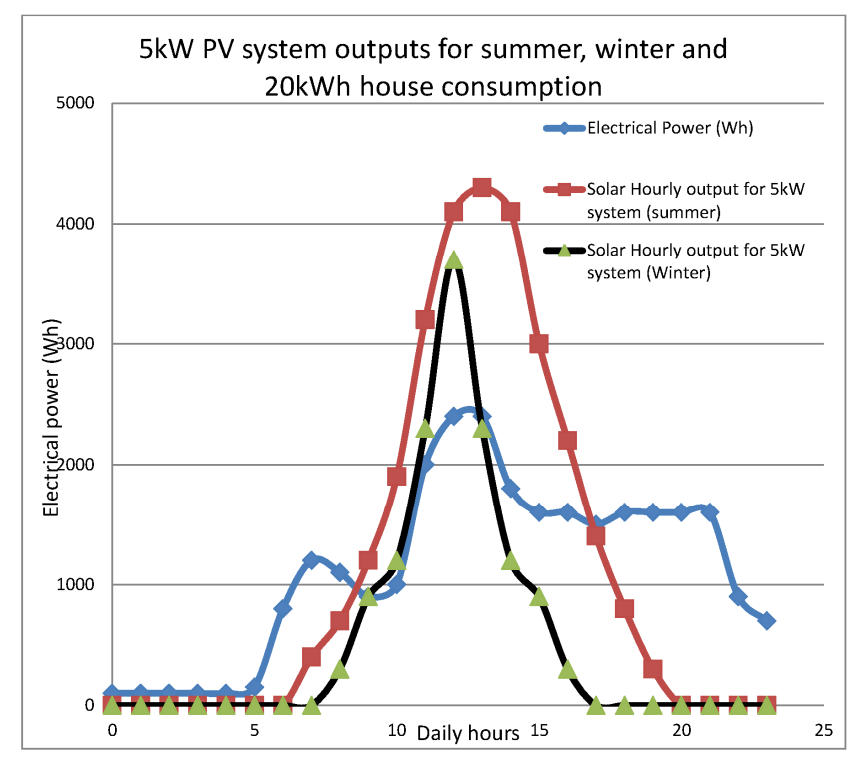

Figure 6. Updated household energy consuption with energy shifting

\section{THEORETICAL DISCUSSION}

Depending on the installed PV solar system, the generated power could exceed the house requirements. However, the house maximum demands located outside the peak electrical output of the solar system. Therefore, without storage facility, the current technologies do not assist in utilizing the generated power to supply the household electrical requirements. As shown in figure 5, the generated power for a working family will be fed into the grid. This system assists the utilities in reducing the generated power during midday period for a sunny day.

The smart home energy management system will shift the power from the peak to midday when possible. Also it predicts the maximum power for the week by taking into consideration the forecast data. This arrangement increases the efficiency of the PV system and reduces the electricity bills. This increased efficiency reduces the environmental impact for power stations and reduces the cost of electrical infrastructure.

\section{CASE STUdy}

The case study is based on the house loading showing in table 1 . The house has $5 \mathrm{~kW}$ PV solar system installed on the roof top. The elements of equation 1 as per table 1 are as follows:

$$
\mathrm{P}=16960 \mathrm{Wh}, \mathrm{K}=7200 \mathrm{Wh}, \mathrm{O}=4400 \mathrm{Wh}
$$

$\mathrm{L}=960 \mathrm{Wh}, \mathrm{M}=2100 \mathrm{Wh}, \mathrm{G}=2300 \mathrm{Wh}$

TABLE I. HOUSEHOLD ELECTRICAL LOADING

\begin{tabular}{|l|c|c|}
\hline & \multicolumn{2}{|c|}{ DC Loading } \\
\hline $\begin{array}{l}\text { Product } \\
\text { Description }\end{array}$ & $\begin{array}{c}\text { Electrical Load } \\
\text { (W) }\end{array}$ & $\begin{array}{c}\text { Electrical Load } \\
\text { Wh/day }\end{array}$ \\
\hline $\begin{array}{l}\text { 290L } \\
\text { refrigeration }\end{array}$ & & 900 \\
\hline $\begin{array}{l}\text { Washing } \\
\text { Machine }\end{array}$ & & 500 \\
\hline Dishwasher & & 700 \\
\hline Dryer & 200 & 900 \\
\hline 1L Kettle & 50 & 200 \\
\hline TV & 10 light (12W) & 500 \\
\hline LED light & 1200 & 960 \\
\hline Air-conditioner & 100 & 7200 \\
\hline Chargers & 1000 & 200 \\
\hline Microwave & 2200 & 500 \\
\hline Oven & Total kWh/day & 4400 \\
\hline \multicolumn{2}{|c}{} \\
\hline
\end{tabular}

Figure 7 shows the standard hourly energy consumption against the $5 \mathrm{~kW}$ solar system outputs for winter and summer. It is clearly shown that the generated PV power only feeds low percentage of the required household.

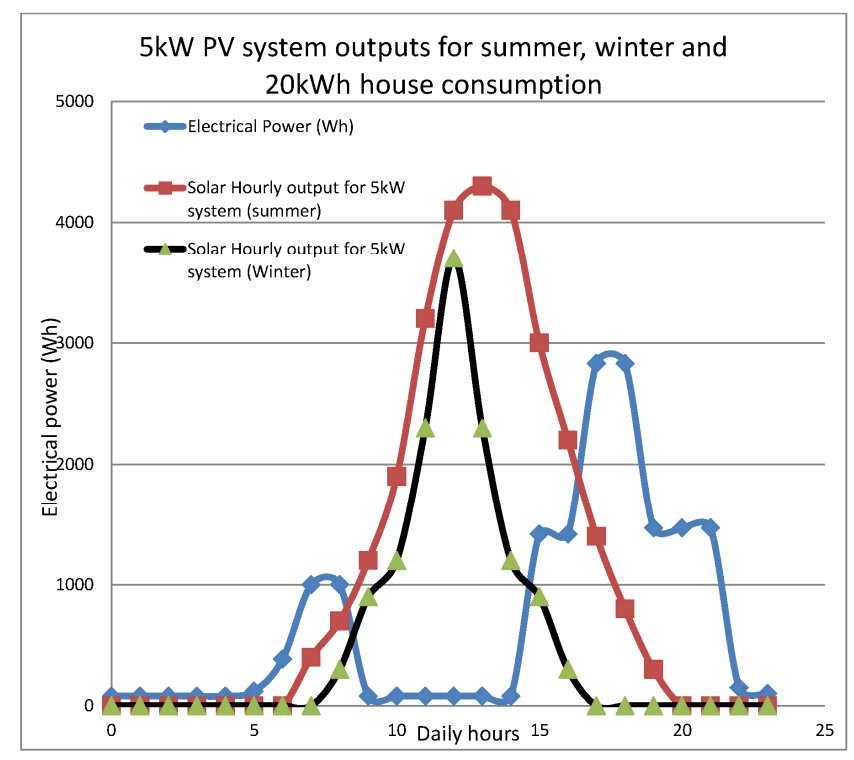

Figure 7. Household electrical power consuptions against PV solar outputs 
For a busy day, the following activities must be performed:

- Washing

- Drying

- Dishwashing

- Cooking

- Air-condition (Cooling or heating)

The smart home energy system analyses the proposed weather forcast for the area. The predictied PV oputput power is shown in table 2.

TABLE II. PREDICTED PV SOLAR SYSTEM WEEKLY OUTPUT

\begin{tabular}{|l|l|l|l|l|l|l|l|}
\hline & Mon & Tue & Wed & Thu & Fri & Sat & Sun \\
\hline kWh & 21.2 & 15.96 & 21.3 & 21.2 & 16.1 & 14.3 & 14.6 \\
\hline
\end{tabular}

The individual chooses the following activities for the week during sunshine hours:

TABLE III. PROPOSED WEEKLY ACTIVITIES

\begin{tabular}{|c|c|c|}
\hline & Proposed activities & $\begin{array}{l}\text { Required PV outputs } \\
(\mathrm{kWh} \text { ) (this includes } \\
\text { general requirements) }\end{array}$ \\
\hline Mon & $\begin{array}{l}\text { Washing, Drying, } \\
\text { Dishwashing Air- } \\
\text { condition, partial cooking }\end{array}$ & 10.1 \\
\hline Tue & $\begin{array}{l}\text { Dishwashing, } \\
\text { condition, partial cooking }\end{array}$ & 9.1 \\
\hline Wed & $\begin{array}{l}\text { Dishwashing, air- } \\
\text { condition, partial cooking }\end{array}$ & 9.1 \\
\hline Thu & $\begin{array}{lr}\text { Washing, } & \text { Drying, } \\
\text { Dishwashing } & \text { Air- } \\
\text { condition, partial cooking }\end{array}$ & 12.3 \\
\hline Fri & $\begin{array}{l}\text { Dishwashing, air- } \\
\text { condition, partial cooking }\end{array}$ & 9.3 \\
\hline Sat & $\begin{array}{l}\text { Dishwashing, air- } \\
\text { condition, partial cooking }\end{array}$ & $13.6^{*}$ \\
\hline Sun & $\begin{array}{l}\text { Dishwashing, air- } \\
\text { condition, partial cooking }\end{array}$ & $13.6^{*}$ \\
\hline
\end{tabular}

* During the weekend, general activities at its maximum during the day (TV, Stereos light,....)

Figure 8 represents the updated hourly consumption as per the proposed smart management concept. It is clearly shown the reduction from the peak afternoon slot. It should be noted that cooling or heating the house during the day using the PV generated power, will reduce the electrical energy consumption for the evening cooling or heating. Furthermore, the system ensures that washing, drying, dishwashing and part of the cooking will be done during peak sun energy.

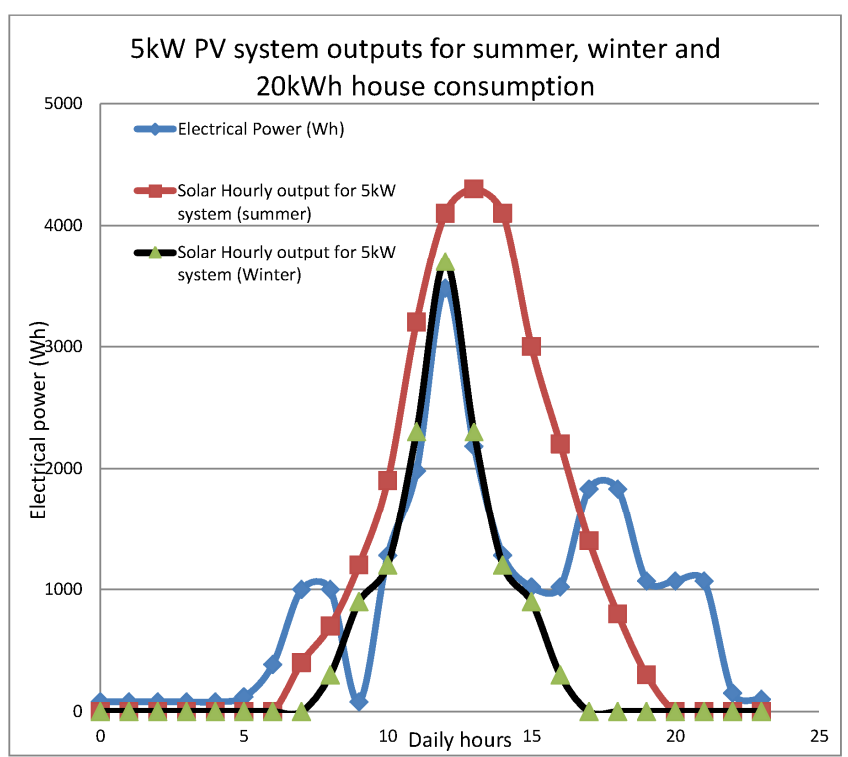

Figure 8. Updated hourly energy consumption to suit the PV solar output

For example, in summer, the ducted air-condition can work on cooling the entire house during the afternoon using the generated electrical energy. This introduces the following benefits:

- Reduce the consumption of the fridge. (Fridge consumes higher electrical power when operating at higher temperature).

- Electronics appliances consume less energy when operating at lower temperature.

- The air-condition required less energy to keep the house cool in the evening and night time, especially that partial of the cooking is completed during the day.

Regarding the partial cooking, it could include the followings:

- Boiling red or white meats for major meals

- $75 \%$ cooking of an oven meal

- $\quad$ Etc...

\section{CONCLUSION}

This paper is an introduction to a sophisticated smart energy management system for residential properties. The proposed system has the abilities to forecast the outputs of the installed PV solar system. Furthermore, it provides the individual with the ability to enhance the system efficiency by maximizing the use of the sun energy.

The case study shows that it is possible to reduce the electrical peak demands for residential properties by using the smart energy management tools. This reduction decreases the required electrical power generated by fossil fuel plants. The outcomes of this arrangement have positive impacts on the environments as well as the electricity bill. 


\section{FUTURE WORKS}

At Western Sydney University, the following systems will be constructed during 2016:

- PV solar system to suit a DC load (with battery storage)

- PC solar system to suit an AC load

- Wind turbine

The installed system allows for the development and testing of the proposed smart energy management tools. Future publication will captures the findings of ongoing works.

\section{REFERENCES}

1. Solar Energy, Chapter 10, published in the Australian Energy Resources Assessment. 2010

2. Clean Energy Council, Accessed 14 of January 2015 at 14:01. https://www.cleanenergycouncil.org.au/technologies/solar-pv.html
3. M. Erol-Kantarci and H.T. Mouftah "Energy efficient information and communication infrastructures in the smart grid: a survey on interactions and open issues" IEEE Communication Survey and Tutorials. Vol. 17, Issue 1. PP. 179-197. 2015

4. Y. Zhang, L. Wang and W. Sun "Trust system design optimization in smart grid network infrastructure" IEEE Transaction on Smart Grid. Vol. 4. Issue 1. PP. 184-195. 2013

5. M. Negnevitsky, D. Niolic and M. De Groot "Demand response for increasing renewable energy penetration in isolated power systems" The Fifth International Conference on Smart Grids, Green Communications and IT Energy-Aware Technologies. Rome, Italy, May 24-29. 2015.

6. Z. Xu, M. Gordon and M. Jacob "Towards a danish power system with $50 \%$ wind- smart grid activities in Denmark" IEEE Power and Energy Society General Meeting. PES'09 PP. 1-8. 2009

7. K. Mitchell "Optimisation of the applications of sustainable energy systems" Ph.D. dissertation, School of Engineering and Industrial Design. Univ. Western Sydney. 2005.

8. K. Mitchell, M. Nagrial and J. Rizk "Simulation and optimization of renewable energy systems". Electrical Power and Energy Systems. Vol. 27. PP. 177-177. 2005 